

\title{
Bone graft materials used in dental implants: A review
}

\author{
V Udayshankar ${ }^{1}$, Vijaya Kumar $\mathbf{R}^{2^{*}}$, Poonam Prakash ${ }^{3}$, Vaibhav Jain ${ }^{4}$ \\ ${ }^{1,4}$ Resident, ${ }^{2-3}$ Reader, ${ }^{1-4}$ Dept. of Dental Surgery, ${ }^{1-4}$ Armed Forces Medical College, Pune, Maharashtra, India
}

\begin{abstract}
Bone grafting is a method by which bone deficient areas are built up with the use of different materials, such as autografts, allografts, alloplasts and xenografts. Bone graft materials are placed in different locations for various indications like in alveolar sockets post extraction, to refill a local bony defect due to trauma or infection, to refill a peri-implant defect due to peri-implantitis, for vertical and horizontal augmentation of the mandible and maxilla. Grafts materials acts as a filler and scaffold to help bone formation and promote wound healing. The dental implant therapy demands sufficient bone volume, biologic quality and certain dimensional properties for long term success. In many situations this makes bone grafting necessary along with the dental implant placement. Despite of the advancements in the field of bone graft materials and implants, the perfect bone reconstruction material for dental implant has not yet developed.

The aim of this article is to provide a contemporary and comprehensive review of the bone graft materials that can be used in dental implants, discussing their properties, advantages, disadvantages, enlightening the present and the future perspective in the field of bone regeneration.
\end{abstract}

Keywords: Bone graft, Dental implant, Graft material.

\section{Introduction}

The goal of modern dentistry is to provide an aesthetic restoration that is supported by a functional and comfortable occlusion while preserving the health of supporting hard and soft tissues. In replacement of missing teeth, the dental implant has become a common treatment modality as it provides improved aesthetics, function hygiene accessibility and osseous preservation. The bone loss, post tooth extraction remains an important issue in dentistry. Anatomically, bone resorption occurs both bucco-lingually and apico-coronally. The first six months after extraction are critical due to the highest rate of bone resorption in either direction. The requirement of suitable bone graft and grafting procedures are equally important pre-requisite for rehabilitation in many patients.

Bone grafting is a surgical procedure that replaces missing bone with material from patient's own body, an artificial, synthetic, or natural substitute. ${ }^{2}$ Bone grafting is possible because bone tissue has the ability to regenerate completely if provided the conditions and environment into which it has to grow. As natural bone grows, it generally replaces the graft material completely, resulting in a fully integrated region of new bone. ${ }^{3}$ The understanding of science of bone grafting is continuously developing with the principles of cellular and molecular biology being incorporated in osseous healing.

This article attempts to review the various bone graft materials used in dental implants. This will help clarify a somewhat murky area for the general practitioner who needs to know more - whether it is to provide guidance to patients, or to increase understanding of the various bone graft materials used in implant treatment.

\section{Rationale for bone grafts ${ }^{4}$}

Placement of implants requires sufficient bone volume and biologic quality. This is due to the macro design of the implant, which demands certain dimensional properties for long-term success. Other factors which make bone grafting necessary are:

1. Resorption of the edentulous ridge post tooth extraction

2. Presence of bony defects due to trauma or infection

3. The need to place implants in strategic sites for functional and aesthetic success. In aesthetic areas, soft tissue requires a bony base since "soft tissue follows hard tissue".

\section{Locations/Indications for bone grafts in implant treatment}

Bone graft materials are placed in different locations for various indications:

1. In alveolar sockets post tooth extraction

2. To fill a local bony defect due to trauma or infection

3. To fill a peri-implant defect due to peri-implantitis

4. For horizontal and vertical augmentation of the mandible and maxilla ${ }^{5}$

\section{Requirements for the bone graft}

Any bone graft material must have properties of osteoconduction, osteo-induction, osteo-promotion and osteogenesis.

1. Osteo-conduction: This occurs when bone graft material serves as a scaffold for new bone growth, which is perpetuated by the native bone. Osteoblasts from the margin of defect that is being grafted, utilize the bone graft material as a framework upon which to

*Corresponding Author: Vijay Kumar R, Dept. of Dental Surgery, Armed Forces Medical College, Pune, Maharashtra, India

Email: dentvk@gmail.com

http://doi.org/10.18231/j.aprd.2019.014 
spread and generate new bone. ${ }^{6}$ In the very least, a bone graft material should be osteoconductive.

2. Osteo-induction: This involves stimulation of osteoprogenitor cells to differentiate into osteoblasts and then begins formation of new bone. The most widely studied type of osteoinductive cell mediators are Bone Morphogenetic Proteins (BMPs). ${ }^{7}$ A bone graft material that is osteo-conductive and osteo-inductive will not only serve as a scaffold for existing osteoblasts but will also trigger formation of new osteoblasts, promoting faster integration of the graft.

3. Osteo-promotion: This involves enhancement of osteoinduction without possession of osteo-inductive properties. For example, enamel matrix derivative enhances the osteo-inductive effect of demineralized freeze-dried bone allograft (DFDBA), but will not stimulate bone growth alone. $^{7}$

4. Osteogenesis: It occurs when vital osteoblasts originating from bone graft material contributes to the growth of new bone along with bone formation. ${ }^{3}$

\section{Factors required for success of bone graft}

Below are the factors upon which success of bone graft depends:

1. Osteoblasts: Only osteoblasts are responsible for new bone formation. For a graft to be successful, the graft matrix must contain osteoblasts. If there is an insufficient number of osteoblasts, the graft will fail. ${ }^{8}$

2. Blood supply: The bone grafting is a type of regeneration and not the repair. The term "repair" implies regaining of lost tissue; regeneration is a biologic process where not only the tissue is regained, but also its form and function. This requires a good blood supply to the graft and surrounding tissue. Blood is needed for cell viability and clot formation. The clot serves as the initial matrix where cells migrate and then serves as anchorage for the osteoblasts. ${ }^{8}$

3. Graft stabilization: Mechanical stresses on the graft during healing can lead to disruption of fibrin clot. Movement of graft material will cause fibrous tissue to fill the defect instead of bone. This is a form of repair and is not true regeneration. Fixation devices like guided bone regeneration (GBR) collagen membranes, titanium mesh and bone screws may be used. ${ }^{8}$

4. No tension on the soft tissue: Bone is the slowest growing tissue. The GBR is based on the separation of grafted site from the surrounding soft tissue. This GBR membrane keeps the faster growing tissues like epithelium, fibrous tissue or gingival connective tissue out of the defect allowing controlled regeneration to occur with vital bone formation. The application of bone graft material into the defect prevents the collapse of the collagen membrane and it acts as a place holder for new regenerating bone and an osteoconductive scaffold for the in growth of blood vessels and osteoblasts ${ }^{9}$.

Table 1: Types of bone grafts: Bone grafts are divided into following types (table 1$)^{10,11}$ :

\begin{tabular}{|c|c|c|c|c|}
\hline $\begin{array}{c}\text { Graft } \\
\text { category }\end{array}$ & Graft type & Advantages & Disadvantages & $\begin{array}{c}\text { Commercially } \\
\text { available }\end{array}$ \\
\hline $\begin{array}{c}\text { Autograft } \\
\text { Isograft }\end{array}$ & $\begin{array}{l}\text { Extraoral: Cranium, Fibula, Iliac } \\
\text { crest, Radius, Rib, Tibia } \\
\text { Intraoral: Anterior maxillary } \\
\text { sinus wall, Anterior nasal spine, } \\
\text { Ascending ramus, Symphysis, } \\
\text { Tuberosity, Palate, }\end{array}$ & $\begin{array}{l}\text { - Osteogenic } \\
\text { - Osteoinductive } \\
\text { - Osteoconductive } \\
\text { - No disease transfer or } \\
\text { immunogenicity }\end{array}$ & $\begin{array}{l}\text { - Donor site morbidity } \\
\text { - Limited quantity } \\
\text { - Possibility of general } \\
\text { anaesthesia and } \\
\text { hospitalization for extra- } \\
\text { oral sites. }\end{array}$ & \\
\hline Allograft & $\begin{array}{l}\text { - Fresh and/or frozen bone, } \\
\text { - FDBA } \\
\text { - DFDBA }\end{array}$ & $\begin{array}{l}\text { - Osteoinductive } \\
\text { - Osteoconductive } \\
\text { - Relative availability }\end{array}$ & $\begin{array}{l}\text { - Possibility of disease } \\
\text { transmission, } \\
\text { immunogenicity } \\
\text { - Variability of properties } \\
\text { depending on productive } \\
\text { method }\end{array}$ & $\begin{array}{l}\text { Allogro, DBX, } \\
\text { DynaBlast, } \\
\text { Dynagraft, } \\
\text { Grafton, }\end{array}$ \\
\hline Xenograft & $\begin{array}{l}\text { - Bovine } \\
\text { - Porcine } \\
\text { - Equine } \\
\text { - Coralline } \\
\text { - Algae }\end{array}$ & $\begin{array}{l}\text { - Osteoconductive } \\
\text { - High availability } \\
\text { - Low cost }\end{array}$ & $\begin{array}{l}\text { - Possibility of disease } \\
\text { transmission, } \\
\text { immunogenicity } \\
\text { - Variability of properties } \\
\text { depending on productive } \\
\text { method }\end{array}$ & $\begin{array}{l}\text { Algipore, } \\
\text { Biocoral, } \\
\text { Bio-Oss, } \\
\text { Cerabone, } \\
\text { Endobon, Gen- } \\
\text { OS, Interporo } \\
200,\end{array}$ \\
\hline $\begin{array}{l}\text { Synthetic } \\
\text { bone } \\
\text { substitute }\end{array}$ & $\begin{array}{l}\text { - } \mathrm{Ca}_{3}\left(\mathrm{PO}_{4}\right)_{2} \\
\text { - Hydroxyapatite } \\
\text { - Calcium carbonate } \\
\text { - Calcium sulphate } \\
\text { - HTR Polymer } \\
\text { - Bioactive glasses } \\
\end{array}$ & $\begin{array}{l}\text { - Osteoconductive } \\
\text { - Availability } \\
\text { - Low cost }\end{array}$ & $\begin{array}{l}\text { - Variability of properties } \\
\text { depending on productive } \\
\text { method }\end{array}$ & $\begin{array}{l}\text { Biogran, } \\
\text { BonePlast, } \\
\text { Calcibone, } \\
\text { Cortoss, } \\
\text { Eurobone, } \\
\text { Perioglass, } \\
\end{array}$ \\
\hline
\end{tabular}




\section{Autograft}

In 1923, Hegedus attempted to use bone grafts for reconstruction of osseous defects. ${ }^{12}$ This method was later revived by Nabers and O'Leary in $1965 .{ }^{13}$ Autografts are considered the 'gold standard' among the various available grafting materials due to their osteogenic properties, maintaining viable cells from the donor to the recipient site as well as osteo-inductive characteristics since a variety of growth factors contribute to the differentiation of mesenchymal stem cells into osteoblasts. ${ }^{14,15}$ Autologous or autogenous bone grafting involves utilizing bone obtained from same individual receiving the graft. Sources of bone include iliac crest, mandibular symphysis, anterior mandibular ramus (coronoid process) and bone removed during osteoplasty and ostectomy. ${ }^{16}$ Whenever block graft will be performed, autogenous bone is the most preferred because there is less risk of graft rejection as the graft is originated from the patient's body. It would be osteoinductive, osteo-conductive as well as osteogenic. Disadvantage of autologous grafts is that additional surgical site is required, another potential location for post-operative pain and complications. Types of autograft include osseous coagulum, bone blend, cancellous bone marrow transplant and bone swaging. ${ }^{17-18}$

\section{Allograft}

Allograft is derived from humans. The difference is that allograft is harvested from an individual other than the one receiving the graft. Allograft bone is taken from cadavers that have donated their bone so that it can be used for living people who are in need of it; it is typically sourced from a bone bank. ${ }^{3}$ They are available as cortical, cancellous or cortico-cancellous grafts, in various shapes and sizes. There are three types of bone allograft available: ${ }^{19}$

1. Fresh or fresh-frozen bone: This is frozen at minus 80 degree centigrade to avoid degradation by enzymes, without further irradiation, lyophilization or demineralization process. It is acellular, possessing the highest osteo-inductive and osteo-conductive properties due to the presence of BMPs. However, this is not used anymore due to disease transmission and high immune response.

2. FDBA: This allograft undergoes dehydration and freezing without demineralization, leading to decreased antigenicity. It has only osteo-conductive potential.

3. DFDBA: This allograft undergoes dehydration, freezing and inorganic part of the bone is eliminated, leaving only the organic part that contains BMPs. These materials exhibit osteo-conductive and inductive features.

The use of allografts for bone repair often requires sterilization and deactivation of proteins which are normally found in healthy bone. The extracellular matrix of bone tissue contains bone growth factors, proteins and other bioactive materials necessary for osteo-induction and successful bone healing. The desired factors and proteins are removed from the mineralized tissue by using a demineralizing agent such as hydrochloric acid. The mineral content of the bone is degraded and the osteo-inductive agents remain in a demineralized bone matrix (DBM).

The advantages of allografts include availability in adequate quantities, sizes and shapes, predictable results and elimination of an additional donor site surgery. On the other hand, disease transmission from the donor to the recipient, although extremely small, cannot be totally excluded and additional testing for HIV, Hepatitis B virus, Hepatitis C virus and Treponema serologic markers should be performed. Higher absorption rate, immunogenic response and less revascularization compared to autologous grafts has been reported among the disadvantages of this grafting category. Finally, due to the fact that a bone allograft is not a standardised tissue since age, gender and medical status of donors may vary in combination with existing diversity of processing procedures in bone banks, interprets why their properties may differ widely. ${ }^{20}$

\section{Xenografts}

These materials derive from donors of a different species relative to the recipient, usually possess osteoconductive features with limited resorptive. The disadvantages are the difference in bone characteristics of graft compared to humans, their processing procedure might affect their physico-chemical properties as in the case of allografts, the possibility of disease transmission and stimulation of immunogenicity. ${ }^{21}$ Two illustrations of xenografts used in dentistry are (i) coral-derived bone substitutes having geometry similar to that of human cancellous bone interconnected macropores $(200-600 \mu \mathrm{m})$ and (ii) demineralized bovine bone grafts, biocompatible and osteoconductive. $^{22}$

1. Coral substitutes: Coral bone grafts have been also applied in jaw defects, exhibiting osteoconductive properties and functioning as carriers for growth factors, improving bone formation. They present initial poor mechanical strength, favourable to blood supply of recipient cite and fast resorption rate. Several studies have reported the ability to implement this material in dentoalveolar reconstruction with encouraging results.

2. Bovine substitutes: Bovine origin bone substitutes were the first xenografts applied to patients. They are commercially available in a wide range of products and is considered among the most documented materials of this category. They have osteoconductive properties, being deproteinized and lyophilized, causing no immune response. However, granules of these materials are considered to be subjected to poor or slow absorption $^{23}$. Processing at high temperatures to avoid immune reactions, allergies and infectious diseases such as spongiform encephalopathy is considered responsible further reduced absorption potential. ${ }^{24,25}$

\section{Alloplastic materials/Synthetic variants}

The enormous progress in the field of biomaterials science, the risk of infectious diseases transmission and finally, efforts to reduce morbidity and cost has led research into the development of a variety of synthetic origin grafts as 
alternatives. These biomimetic materials characterized by osteoconductive, with no osteoinductive or osteogenic potential on their own. They act as a three-dimensional scaffold to support cell growth and bone formation, increase cell adhesion and proliferation. Flexible hydrogelhydroxyapatite (HA) composite which has a mineral to organic matrix ratio, approximating that of human bone. Artificial bone can be created from ceramics such as calcium phosphates (e.g., HA and tricalcium phosphate), bio-glass and calcium sulphate as they are biologically active depending on solubility in physiological environment. ${ }^{26}$ These materials combine with growth factors, ions such as strontium or mixed with bone marrow aspirate to increase biological activity. The presence of elements such as strontium can result in higher bone mineral density (BMD) and enhanced osteoblast proliferation. ${ }^{3}$

Calcium phosphate: These materials have gained special interest due to their composition similarity with natural bone. Hydroxyapatite (HA) and tricalcium phosphate (TCP) are the most important players of this category, further classified into ceramics and cements. The ceramics are subjected to heat treatment called sintering, further driving to a porous and solid material. Cements are produced in the form of paste which hardens after application within the bone defect site. ${ }^{27}$

Tricalcium phosphate (TCP) exhibits good biocompatibility and osteo-conductivity, but lacks osteogenic or osteoinductive properties. It's porous composition permits phagocytosis, absorption, vascularization and bone regeneration. In accordance to other calcium phosphate preparations it has been found to be brittle and weak under tension and shear, but resistant to compressive loads. Compared to HA, TCP is more quickly resorbable and less mechanically stable. ${ }^{28}$

$\mathrm{HA}$, representing the main structural inorganic component of bones and teeth has excellent biocompatibility with the human body and can therefore be used as a bone graft. HA crystals possess mainly osteo-conductive properties and low resorption rate while they are brittle and fracture prone on shock loading. This bone implant has been established as an excellent carrier of osteoinductive growth factors and osteogenic cell populations. ${ }^{29}$ Biphasic calcium phosphate (BCP) results from the mixing of TCP and HA in various concentrations in order to attain desired mechanical properties and absorption rate. ${ }^{30}$

Calcium sulphate: Calcium sulphate, commonly known as Paris gypsum, was first used as a bone substitute in 1892 for the filling of long bones tubular cavities. ${ }^{31}$ It is provided in the form of cement or granules, both products exhibiting biocompatibility, bioactivity, tolerability, carrier material capability, osteo-conductivity, easy handling and low cost. Rapid absorption of the material has been noted than the rate of bone formation. In the field of dentistry, it has been extensively applied in periodontal, dentoalveolar and tooth extraction defects. ${ }^{32}$

Hard tissue replacement (HTR) polymeric substitutes: The most important of the polymers used in bone augmentation is polymethyl methacrylate, a porous biomaterial exhibiting osteoconductive properties, compressive strength and elasticity similar to cortical bone, but not resorbable. The high temperature which is developed during the polymerization, depending on the exact cement composition may create thermal bone necrosis, damage of blood circulation and membrane formation between bonecement interfaces. ${ }^{27}$

Bioactive glass: Bioactive glass material composed of active silicate-based glass, this implant exhibits significantly greater strength compared to calcium phosphates. It is capable of forming a strong bond between the glass and the host bone through hydroxyapatite crystals, a phenomenon called bioactivity. The resorption of bioactive glass is variable, based upon the relative amounts of components like sodium oxide, calcium oxide, silicon dioxide and phosphorous present. ${ }^{33}$

\section{Conclusion}

The subject of bone grafts for implant procedures is complex and many a times confusing for the dental surgeon, let alone the restorative dentist and patient. This article has attempted to simplify and clarify the basics. Equipped with this information, the general dentist can be a better judge of the materials used. This information can prepare the clinician for counselling patients on the surgical procedures to be performed and further exploration of simple bone grafting procedures that can be done in the general practice.

\section{Source of Funding}

None.

\section{Conflict of Interest}

None.

\section{References}

1. Hoexter DL. Bone regeneration graft materials. J Oral Implantol 2002;28(6):290-4.

2. The glossary of prosthodontics terms. J Prosthet Dent 2017: 63.

3. Kumar P, Vinitha B, Fathima G. Bone grafts in dentistry. $J$ Pharm Bioallied Sci 2013;5(1):125-7.

4. Klein MO, Al-Nawas B. For which clinical indications in dental implantology is the use of bone substitute materials scientifically substantiated? Eur J Oral Implantol 2011;4:1129.

5. Schug J, Kirste M, Huber A, Hollay HC, Troedhan A, Leventis $\mathrm{MD}$ et al. Post extraction alveolar ridge preservation: scientific background, minimally invasive treatment protocols and expert reports using alloplastic biomaterials. Sunstar Guidor 2014;1.

6. Laurencin C, Khan Y, El-Amin SF. Bone graft substitutes. Expert Rev Med Devices 2006;3:49-57.

7. Mulconrey DS, Birdwell KH, Flynn J, Cronen GA, Rose PS. Bone morphogenic protein (RhBMP-2) as a substitute for iliac crest bone graft in multilevel adult spinal deformity surgery: Minimum two- year evaluation of fusion. Spine (Phila $\mathrm{Pa}$ 1976) 2008;33:2153-9.

8. Smiler D, Soltan M. The bone-grafting decision tree: a systematic methodology for achieving new bone. Implant Dent 2006;15(2):122-8. 
9. Rothamel D. Clinical aspects of novel types of collagen membranes and matrices- Current issues in soft and hard tissue augmentation. Eur J Dent Implantologists 2012.

10. Liu X, Shi B, Zheng Q, Li C. Alveolar bone grafting and cleft lip and palate. Plast Reconstr Surg 2017;140(2):359-60.

11. Malinin TI, Temple HT, Garg AK. Bone allografts in dentistry: a review. Dent 2014;4:199.

12. Hegedus $Z$. The rebuilding of alveolar process by bone transplantation. Dent Cosmos 1923;65:736.

13. Nabers CL, O'leary TJ. Autogenous bone transplants in the treatment of osseous defects. J Periodontol 1965;36:5-14.

14. Sakkas A, Wilde F, Heufelder M, Winter K, Schramm A. Autogenous bone grafts in oral implantology-is it still a "gold standard"? A consecutive review of 279 patients with 456 clinical procedures. Int J Implant Dent 2017;23.

15. Titsinides S, Agrogiannis G, Karatzas T. Bone grafting materials in dentoalveolar reconstruction: A comprehensive review. Japanese Dent Sci Rev 2018;55(1):26-32.

16. Hiatt WH, Schallhorn RG. Intraoral transplants of cancellous bone and marrow in periodontal lesions. J Periodontol 1973;44:194-208.

17. Robinson E. Osseous coagulum for bone induction. $J$ Periodontol 1969;40:503-10.

18. Diem CR, Bowers GM, Moffitt WC. Bone blending: A technique for osseous implants. J Periodontol 1972;43:295-7.

19. Centres for disease control and prevention. Septic arthritis following anterior cruciate ligament reconstruction using tendon allografts: Florida and Louisiana, 2000. MMWR Morb Mortal Wkly Rep 2001;50:1081-3.

20. Shibuya N, Jupiter DC. Bone graft substitute: allograft and xenograft. Clin Podiatr Med Surg 2015;32:21-34.

21. Tovar N, Jimbo R, Gangolli R, Perez L, Manne L, Yoo D, et al. Evaluation of bone response to various an organic bovine bone xenografts: an experimental calvaria defect study. Int $J$ Oral Maxillofac Surg 2014;43:251-60.

22. Venkataraman N, Bansal S, Bansal P, Narayan S. Dynamics of bone graft healing around implants. J Int Clin Dent Res Organ 2015;7(3):40.

23. Cypher TJ, Grossman JP. Biological principles of bone graft healing. J Foot Ankle Surg 1996;35(5):413-7.

24. Jensen SS, Broggini N, Hjorting-Hansen E, Schenk R, Buser D. Bone healing and graft resorption of autograft, an organic bovine bone and beta-tricalcium phosphate. A histologic and histomorphometric study in the mandibles of mini pigs. Clin Oral Implants Res 2006;17(3):237-43.

25. Tauro JC, Parsons JR, Ricci J, Alexander H. Comparison of bovine col-lagen xenografts to autografts in the rabbit. Clin Orthop Relat Res 1991;266:271-84.

26. Centres for disease control and prevention (CDC). Update: Allograft-associated bacterial infections: United States, 2002. MMWR Morb Mortal Wkly Rep 2002;51:207-10.

27. Wang W, Yeung KWK. Bone grafts and biomaterials substitutes for bone defect repair: a review. Bioact Mater 2017;2(4):224-47.

28. Yu X, Tang X, Gohil SV, Laurencin CT, Raymond T. Biomaterials for bone regenerative engineering. Adv Healthc Mater Adv Health Mater 2016;4(9):1268-85.

29. Meffert RM, Thomas JR, Hamilton KM, Brownstein CN. Hydroxyl apatite as an alloplastic graft in the treatment of human periodontal osseous defects. J Periodontol 1985;56(2):63-73.

30. Daculsi G, Le Geros R, Nery E, Lynch K, Kerebel B. Transformation of biphasic calcium phosphate ceramics in vivo: ultrastructural and physicochemical characterization. $J$ Biomed Mater Res 1989;23:883-94.

31. Pecora G, Andreana S, Margarone JE, Covani U, Sottosanti JS. Bone regeneration with a calcium sulfate barrier. Oral Surg Oral Med Oral Pathol Oral Radiol Endod 1997;84(4):424-9.

32. Crespi R, Capparè $P$, Gherlone E. Magnesium-enriched hydroxyapatite compared to calcium sulfate in the healing of human extraction sockets: Radiographic and histomorphometric evaluation at 3 months. $J$ Periodontol 2009;80(2):210-8.

33. Giannoudis PV, Dinopoulos H, Tsiridis E. Bone substitutes: an update. Injury 2005;36(3):20-7.

How to cite this article: V Udayshankar, RV Kumar, Prakash P, Jain V. Bone graft materials used in dental implants: A review. Ann Prosthodont Restor Dent 2019;5(3):58-62. 